\title{
DANÇANDO, CANTANDO E CONTANDO HISTÓRIAS, OS VELHOS DO MATO GRANDE/RN EDUCAM ATRAVÉS DOS GESTOS E DA ORALIDADE
}

\author{
M. E. S. P. AQUINO ${ }^{1 *}$ e K. O. PORPINO ${ }^{2}$ \\ ${ }^{1}$ Instituto Federal do Rio Grande do Norte \\ ${ }^{2}$ Universidade Federal do Rio Grande do Norte \\ elizabete.paiva@ifrn.edu.br*
}

Artigo submetido em outubro/2014 e aceito em novembro/2014

DOI: $10.15628 /$ holos.2014.2519

\section{RESUMO}

Compartilho fragmentos da dissertação que trata de uma Educação que se concretiza na oralidade e na gestualidade dos velhos mestres brincantes do território do Mato Grande/RN e propõe uma reflexão sobre o trânsito entre esses saberes e a educação escolar. Assim, assume os seguintes objetivos: identificar os velhos mestres brincantes da região do Mato Grande, registrar suas experiências de vida relacionadas às brincadeiras da tradição e o modo como os mesmos percebem essas referências na atualidade, investigar e registrar práticas educativas que considerem as brincadeiras dos velhos na educação atual. Assim realiza um mapeamento do território do Mato Grande/RN a partir do qual identifica dezessete velhos brincantes. Considera e registra suas experiências com os folguedos populares e a partir desses registros passa a discutir os modos pelos quais a tradição oral do Mato Grande pode ser reconhecida a partir das ações: narrar, cantar e dançar. Por último, lança um olhar para a relação entre o velho, o conhecimento da tradição e a educação sistematizada.

PALAVRAS-CHAVE: brincadeiras, velhos, oralidade, educação.

\section{DANCING, SINGING AND TELLING STORIES, THE OLD MATO GRANDE/RN EDUCATE THROUGH GESTURES AND ORALITY}

\begin{abstract}
Share fragments of the dissertation is about an Education which is made concrete through orality and gestuality of the elderly joking masters of the territory of Mato Grande/RN and proposes a reflection about the exchange between these two knowledges and school education. Thus, it presents the following objectives: identifying the joking elderly in the region; recording their life experiences related to the jokes of the tradition and the way they realize such references at present; besides investigating and recording educative practices which
\end{abstract}

consider the elderly's jokes at the present education. The mapping of the territory of Mato Grande/RN has enabled the identification of seventeen joking elderly people. It considers and records their experiences with the popular amusements and from them, it discusses the ways through which the oral tradition in Mato Grande may be recognized in actions, namely, narrating, singing and dancing. Finally, it also focuses the relation between the elderly, the knowledge of the tradition and the systemized education.

KEYWORDS: Jokes, Elderly, Orality, Education. 


\section{INTRODUÇÃO}

Este trabalho constitui-se como um recorte da dissertação de mestrado apresentada ao programa de Pós-Graduação em Educação da Universidade Federal do Rio Grande do Norte (UFRN) no ano de 2013. A intenção em pesquisar foi motivada pela percepção do desconhecimento dos discentes do Instituto Federal de Educação, Ciência e Tecnologia do Rio Grande do Norte (IFRN), campus João Câmara, pelas danças da tradição que fazem parte da memória do Território do Mato Grande, como também pelo encontro e convívio com os velhos de João Câmara, participantes do projeto de extensão "Vida saudável", projeto este que coordenei conjuntamente com uma equipe interdisciplinar durante o período de 2011 a 2013. Através de um mapeamento no território do Mato Grande/RN ${ }^{1}$, elencamos cinco municípios para compor este mapeamento (João Câmara, São Miguel do Gostoso, Caiçara do Norte, Poço Branco e Ceará-Mirim), nestes espaços, encontramos dezessete brincantes que através da oralidade apresentaram uma diversidade de contos, cantos e danças, que se fizeram presentes na forma de vozes e gestos.

Essas referências fazem parte e constituem a memória social e cultural da região, nas experiências de vida dos velhos brincantes perpassam processos de trocas e transformações culturais significativas. A intenção de registrar as produções culturais advindas da experiência de vida dos brincantes foi o primeiro passo dado para propor ações educativas que pudessem religar os saberes da tradição do Mato Grande aos conteúdos e procedimentos instituídos pelas escolas dessa região, para que tais saberes não fiquem apenas na oralidade e no espaço de moradia dos mais velhos, mas também transitem nos espaços educativos institucionalizados. Ao abordar a temática cultura de movimento nas aulas de Educação Física, percebemos que os jovens de diversos municípios que constituem o Mato Grande desconheciam ou ignoravam completamente as danças da tradição de sua região que, outrora, faziam-se presentes nas suas comunidades. Medeiros (2010) afirma que as danças da tradição são danças que se mantêm ao longo do tempo na memória do povo. Elas permanecem mesmo quando seus sentidos mudam com o tempo. Ao entrar em contato com uma pluralidade cultural encontrada no território, percebemos que as danças da tradição observadas no Mato Grande não se resumiam aos gestos coreografados, mas traziam consigo uma diversidade de narrativas de vida, contos, melodias, encenações, personagens, além da gestualidade da própria dança.

Chamado de folguedo, colocado por Cascudo (1988), ou danças dramáticas, por Andrade (2002), mostram essa mescla de formas expressivas que são as danças tradicionais. Segundo Cascudo (1988), o folguedo é uma manifestação folclórica que reúne as características de um bailado, com músicas, figuras, enredos e temática. Para Andrade (2002), as danças dramáticas são manifestações populares, como espetáculos que associam música, drama e manifestação corporal. Assumiremos na pesquisa o termo "brincandeiras" para estas manifestações, pois é assim que os brincantes desse território a consideram.

Como aporte teórico compreendemos a partir de Zumthor (2005) que é pela tradição oral que essas pessoas produziram esses conhecimentos e que se utilizaram da voz e da performance para compartilhar essas sabedorias que foram e vão sendo transmitidas de geração em geração.

\footnotetext{
${ }^{1} \mathrm{O}$ território do Mato Grande integra a mesorregião do agreste potiguar. Possui um aglomerado de 16 municípios, abrangendo uma área de $5.758,60 \mathrm{Km}^{2}$ e uma população de 226.540 habitantes.
} 
Entendemos como ações educativas essas experiências vividas pelos velhos brincantes, assim como Vieira (2012) e Viana (2006) o fizeram. Através dos cantos, contos e danças são vividas experiências de criatividade, coletividade e união, aspectos observados como raros na educação atualmente.

Destituídos da escrita, os brincantes carregam nas suas memórias corporais a capacidade de reconstruir as brincadeiras, atribuindo diversos sentidos e significados sejam; elencando as letras das canções, a seqüência dos passos e todos os detalhes das apresentações que suas lembranças permitiram descrever, ritos, signos e símbolos que transcendem o tempo e a história. Partimos de algumas questões de investigação: como as experiências dos velhos brincantes do Mato Grande podem ser valorizadas como conhecimento necessário à educação institucionalizada? $\mathrm{Na}$ condição de professores, como podemos agir para que, na velhice, o brincante da tradição oral possa ainda ser reconhecido como imprescindível na educação dos jovens? E como objetivos principais, pretendemos identificar os brincantes do Mato Grande, registrar suas experiências com as brincadeiras da tradição, investigar e articular práticas educativas que considerem as brincadeiras dos velhos na educação atual.

\section{REVISÃO BIBLIOGRÁFICA}

Para o mapeamento do Território, foi necessário realizar a descrição dos municípios, observações feitas a partir das inferências da mobilidade urbana proposta por Augé (2010), a articulação sobre a geografia, história e toponímia do Rio Grande do Norte seguindo os passos de Cascudo (1988) e as astúcias e táticas das pessoas ordinárias atribuídas por De Certeau (2012). O mapeamento foi realizado em cinco municípios ressaltando 17 brincantes para dialogar com o estudo.

Encontramos a maioria dos brincantes na zona rural, moradores de assentamentos e distritos. Neste território também se encontra uma comunidade quilombola (Acauã) no município de Poço Branco e uma comunidade indígena (amarelão) no município de João Câmara. O bioma característico do Mato Grande é a caatinga, apresentando, ainda, uma faixa da mata atlântica. Essa área está com uma grande expansão no setor turístico, da agroindústria, do comércio pesqueiro, da energia eólica e das riquezas naturais. A diversidade apresentada do território nos fez acrescentar a dissertação um toponímico geral, um glossário e anexos dos contos e canções transcritos.

Aproximamos as narrativas dos velhos ao ensaio o narrador de Benjamin (2012) e o poder da voz viva em Zumthor (2005). Benjamin assinala que as melhores narrativas escritas são as que menos se distinguem das histórias orais contadas por narradores anônimos. Falando sobre a arte de narrar, Benjamin (2012), em seu ensaio "O narrador", já alertava que "são cada vez mais raras as pessoas que sabem narrar devidamente" (Benjamin, 2012, p. 197). Ele atribui que esse declínio das narrativas se dá em decorrência da falta de experiências, que estão inscritas em uma tradição em extinção. Ele já observava que essa arte estava em processo de decadência e que as melhores narrativas são aquelas que mais se aproximavam das histórias orais contadas pelos indivíduos que se encontravam no anonimato.

Tecendo referência a Benjamin, encontramos Vaz (2004), que em seu texto "memória e progresso" analisa a procura dos gestos e sentidos possivelmente encontrados em uma narrativa 
histórica do corpo e suas expressões no mundo contemporâneo. Colocando-se como interlocutor de Benjamin, esse autor aponta a narrativa como comunicação de experiências entre quem narra e quem ouve. Nessa relação estão presentes, além das palavras, os gestos imbuídos de sentimentos. Narrar é reelaborar a história, é o relato de uma experiência corporalmente vivida, mesmo que seja a de ouvir a narração. Pensando nessas proposições suscitadas por Benjamin e, posteriormente, por Vaz, faço a ponte com as narrativas de D. Paulinha, de Gostoso, que, aos 74 anos, aposentada, sentada em uma cadeira embaixo da castanhola em frente a sua casa, afirma: "De São Miguel sei tudo, pois ouvia as histórias da minha avó e ficou tudo encasquetado no juízo e nunca esqueci. A minha avó contava as histórias que ouvia do seu avô Miguel Felix Martins". Nos entremeios das suas narrativas, D. Paulinha as recheava com gestos e cantorias, numa mistura que pode suscitar encanto ou compaixão.

Narrando os contos, estes brincantes cantavam, e os cantos eram recheados de gestos e movimentos, entrelaçados como uma teia. Zumthor (2012) afirma que o canto expande a capacidade da voz e complementa: se eu canto, eu me afirmo, reinvindico a totalidade do meu lugar, do meu estar no mundo. Nas falas dos brincantes do Mato Grande, o canto se coloca como o elemento central, que guia as brincadeiras, cadencia a sequência nas apresentações. É um dos principais elementos da brincadeira, o primeiro que os brincantes aprendizes devem aprender. Ele permeia todas as brincadeiras citadas pelos entrevistados. Ele é o aspecto motivacional, podendo ser grave, agudo, sonoro, imponente, suave, dançante, melodioso, lento, rápido, curto, extenso, intermitente, pausado. Nos grupos, é aprendido como tradição, transmitido de geração em geração, ou criado a partir da realidade em que está inserido.

Outra ação que elencamos como educativa para os brincantes foi o dançar. Para Garaudy (1980) não é apenas com os olhos que a apreciamos e a acompanhamos, mas também com os movimentos que expressamos com o nosso próprio corpo. "É que dança não é apenas uma arte, mas um modo de viver" (Garaudy, 1980, p.13). Com essa afirmativa, esse pensador francês, em sua obra "Dançar a vida", expõe que a dança se constitui desde a criação pelos povos mais antigos como uma forma de expressar as relações do homem com a natureza e a sociedade. Dançar é viver, é celebrar, é participar. Assim, esse autor nos provoca a reflexão sobre a essência da dança que para ele é, a um só tempo, conhecimento, arte e religião. Ele ainda acrescenta que, desde os primórdios das sociedades, o homem se afirma como membro de uma comunidade através dos cantos e das danças.

A dança ainda implica participação, pois, para Garaudy (1980), não é apenas com os olhos que a apreciamos e a acompanhamos, mas também com os movimentos que expressamos com o nosso próprio corpo. Ele ressalta que a dança mobiliza, de alguma forma, certo sentido, pelo qual a nossa consciência se faz presente pela posição e tensão de nossos músculos, como os canais semicirculares de nosso ouvido, que nos dão consciência de nosso equilíbrio e o comandam. Essa experiência se constitui um dos ensinamentos que a dança pode provocar e transformar em nossa própria vida a partir da criação do outro e com o outro. Para Porpino (2006), a dança faz sentido e cria novos sentidos, tanto para aquele que dança quanto para aquele que aprecia, como uma teia de significados.

Percebemos que, ao dançarem, os personagens comunicam todo um universo de códigos e símbolos, fazendo-nos refletir sobre a vivacidade presente nos velhos brincantes, corpos que não querem silenciar, corpos que brincam o Pastoril, o Coco, os Congos, a Capoeira, o Boi e tantas outras brincadeiras da tradição do Mato Grande/RN. Esses sentimentos e emoções aflorados 
convergem com a reflexão que Viana (2006) faz sobre a sua vivência e pesquisa sobre o Boi do Maranhão:

\begin{abstract}
Um corpo vivo, que trabalha, sente prazer, sofre de amor, sente fome, molda, transforma, conforma, liberta-se. Corpos onde se leem todas as informações geradas pelo universo da cultura no tempo e no espaço. Universo que mantém vivo este corpo e ao mesmo tempo é sustentado por ele. Corpos que dançam e se movimentam com emoção e desejo. Corpos que gesticulam, saltam, cortejam, enfim, vivem (VIANA, 2006, p. 171).
\end{abstract}

Ainda na perspectiva do pensamento desse autor, ele afirma que homens e mulheres, ao dançarem, realizam movimentos e criam sentidos e significados neles próprios, pois dançando o homem brinca, extravasa emoções, transforma espaços, inventa e cultiva rituais. "O tempo e espaço passam a ser ritualizados por personagens que realizam histórias, armazenam acontecimentos e alimentam a cultura como um grande arquivo, no qual espelham e projetam mensagens" (VIANA, 2006, p.172).

Entre vozes, gestos, linguagens e sons fomos tecendo os saberes do Mato Grande. Encontramos na performance elencada por Zumthor (1993) esse movimento sensorial entre o intérprete e o ouvinte. Compreendermos o imaginário, sermos atraídos pela performance presente nos brincantes, que, ao brincar, comunicam o universo dos folguedos, levou-nos a buscar o termo performance colocado por Zumthor (1993), a presença corporal do ouvinte e do intérprete, como uma presença plena carregada de poderes sensoriais simultaneamente. Ela se afirma pela forma e o alcance da comunicação, pois, com efeito, rege o tempo, o lugar, a finalidade da transmissão, a ação do locutor e, em ampla medida, a resposta do público. "Performance é reconhecimento. A performance realiza, concretiza, faz passar algo que eu reconheço, da virtualidade à atualidade" (Zumthor, 1993, p.31). Ela, além de comunicar, modifica o conhecimento.

O conceito de performance de Zumthor é adequada e me faz compreender a realidade investigada. Ouvir as canções, a descrição das brincadeiras, as gestualidades que acompanham as narrativas e as danças, a partir do contato com os brincantes, levam-nos a compreender o pensamento de Zumthor (1993):

A "formação" se opera pela voz, que carrega a palavra; a primeira "transmissão" é obra de um personagem utilizando em palavra sua voz viva, que é necessariamente ligada a um gesto. A "recepção" vai se fazer pela audição acompanhada da vista, uma e outra tendo por objeto o discurso assim performatizado: é com efeito, próprio da situação oral, que transmissão e recepção ai constituíam um ato único de participação, co-presença, esta gerando o prazer. Esse ato único é a performance (ZUMTHOR, 1993, p. 65).

Assim, entre narrativas, canções e danças constituímos os saberes encontrados no Mato Grande pelas experiências dos brincantes que no envelhecimento encontraram sabor em compartilhar os seus saberes por meio da oralidade. 


\section{METODOLOGIA}

Para identificar e registrar as vozes dos brincantes traçamos visitas a campo que perdurou de agosto de 2011 a fevereiro de 2013. Acompanhada por alunos bolsistas e moradores dos municípios escolhidos, traçamos roteiro e definimos entrevistas semi-estruturadas. Várias viagens foram feitas sempre munidos de cadernos, canetas, máquinas digitais, filmadoras, gravadores e celulares. Assim, registros eram feitos do que se observava nas cidades, mobilidades urbanas, aspectos do cotidiano, espaços de lazer. Observávamos quais eram as suas particularidades e/ou divergências, a sua principal economia e história e como encontrávamos os brincantes; seu estado de humor, condição de moradia, seus arranjos familiares, seus objetos de uso, seu estado de saúde, sua memória, sua oralidade, suas atividades laborais e de lazer. Assim, destacamos na figura 1, a imagem de D. Nazaré, Mestra do Pastoril de São Miguel do Gostoso.

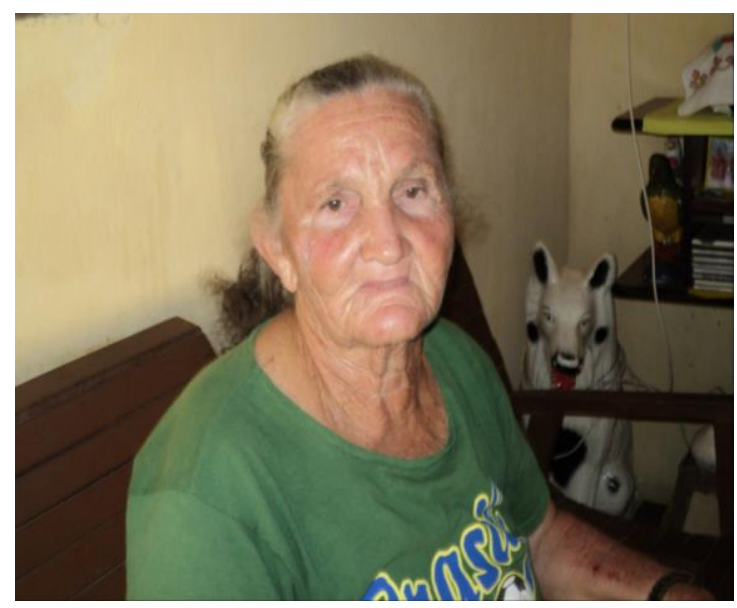

Figura 1: D. Nazaré (Mestra do Pastoril de São Miguel do Gostoso)

Lá nas suas moradias, longos diálogos foram construídos, conversávamos como haviam aprendido a brincadeira, o que sentiam quando brincavam, como se caracterizava a brincadeira, quem fazia parte dela, quais adereços e figurinos eram utilizados, como ensinavam a brincadeira para os mais jovens. Com a devida autorização dos entrevistados, as entrevistas eram gravadas, filmadas e fotografadas. Alguns brincantes disponibilizaram parte do seu acervo pessoal como: fotografias e vídeos, para enriquecimento da pesquisa. Em relação aos entrevistados, algumas informações iniciais foram importantes: nome, idade, naturalidade, profissão, como era constituída sua família, com quem morava atualmente.

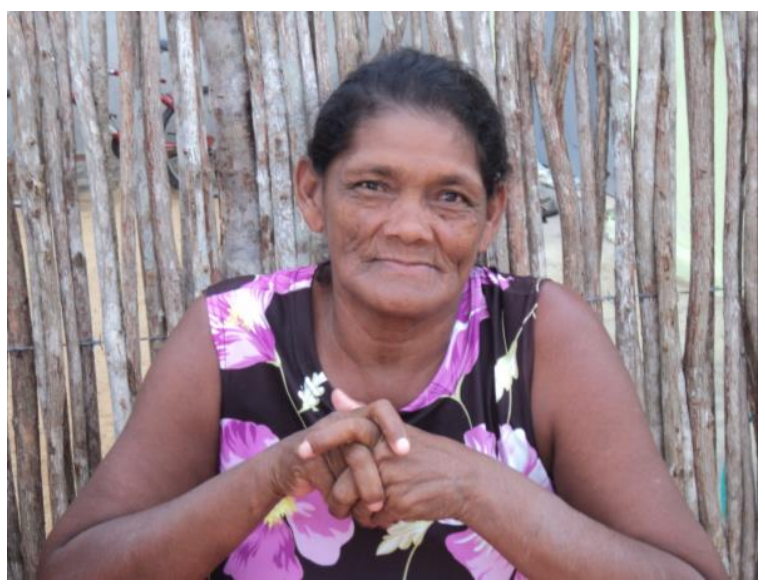

Figura 2: D. Maria Teixeira (a Diana do Pastoril de São Miguel do Gostoso) 
Nestes encontros, selecionamos 11 mulheres e 6 homens, pessoas com algumas características diversas: moradores do território do Mato Grande, faixa etária entre 60 e 98 anos de idade, descendentes de negros, índios e lusitanos, encontramos pessoas com baixa escolaridade, agricultores, pescadores, artesãos, aposentados. Alguns ociosos e depressivos, pessoas sofridas por terem passado fome, por terem perdido filhos. Aprenderam as brincadeiras com os mais velhos da família e alimentam esperança em dar continuidade as mesmas. Dentre as particularidades observadas entre os brincantes, destacamos: a capacidade de lembrar de todos os passos das danças, sua formação e organização, da seqüência dos cantos, entonação das vozes, de acordo com os ritmos, a criatividade em adequar as musicas aprendidas a realidade sóciohistórica do lugar, a estética nas apresentações (figurino, maquiagem, adereços).

Para melhor exemplificar a canção que se refere à realidade sócio-histórica do lugar, destacamos a jornada do Pastoril que falava da rivalidade entre dois grupos de pastoril que tinha em São Miguel do Gostoso na década de 50 do século XX. Esta jornada era cantada pela mãe de D. Maria, que era a Diana do Pastoril:

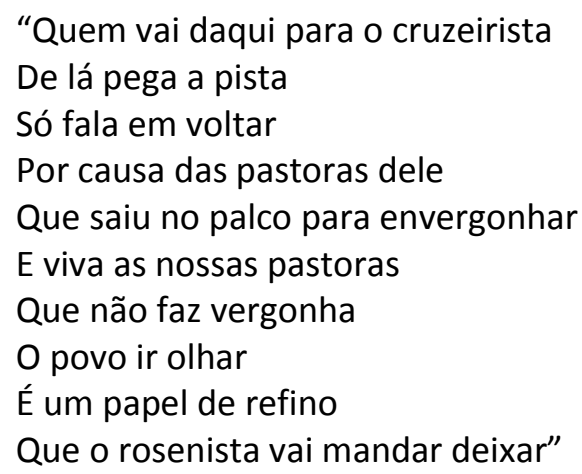

O mapeamento foi realizado em cinco municípios, entre eles temos municípios litorâneos e interioranos; João Câmara, Poço Branco, Caiçara do Norte, Ceará-Mirim e São Miguel do Gostoso. Entrevistamos diversos brincantes e tivemos acesso a uma pluralidade de brincadeiras, porém, selecionamos 17 mestres, referências culturais nas suas comunidades. Em Ceará-Mirim: o Boi de Reis de Matas do Mestre Luis Chico, os Congos de Guerra de Tabuão do Mestre Tião, a Capoeira do Mestre Pequeno. Em Poço Branco: o Pastoril da quilombola Francisca Catarina da Silva e os bonecos do João Redondo do Sr. João Santana. Em João Câmara; os Contos de D. Emilia. Em Caiçara do Norte: o Coco de Roda de D. Maria do Carmo, o Pastoril de D. Baiquinha e D. Socorro e as Baianas de D. Mocinha. Em São Miguel do Gostoso: o Boi de Reis do Seu Zé Marciano e Seu Chico Felipe, o Pastoril de D. Maria Teixeira, D. Maria do Carmo e D. Nazaré e os Contos de D. Neném de Lala e D. Paulinha.

Após reunir um extenso material escrito e imagético sonoro para análise, elencamos como ações educativas o narrar, o cantar e o dançar, que foram descritas através das vozes e gestos. Observamos que, nos cantos reunidos do Mato Grande, algumas estratégias eram utilizadas pelos brincantes. Percebemos, ao analisar os vídeos e transcrever as narrativas, os contos e os cantos, itens que se desvelam desde a composição até a apresentação destes, seja pela alternância dos ritmos presentes, por exemplo, em uma jornada do Pastoril que baila pelo samba, marcha, rumba e valsa, seja pelos intervalos entre o canto alternado com o recitativo. Entre os brincantes que muito contribuíram com suas cantorias, citamos Francisca (Poço Branco), D. Maria Teixeira (Gostoso), D. Paulinha (Gostoso), D. Maria do Carmo (Caiçara do Norte) e D. Baiquinha (Caiçara do 
Norte). Elas não sabem descrever quem são os autores dos cantos; aprenderam com a tradição e os modificaram. Para Zumthor o intérprete é aquele que se percebe na performance, a voz e o gesto, pelo ouvido e pela vista. "Ele pode ser também compositor de tudo ou parte daquilo que ele diz ou canta" (Zumthor, 2010, p.239).

Corpos sofridos que já sentem o processo do envelhecimento avançar, corpos que muito trabalharam, que têm muitas histórias para contar. Corpos femininos que, na época do patriarcado, só serviam para reproduzir, mas na Modernidade já podiam gerir a casa e os filhos. Corpos que, na contemporaneidade, reproduzem, trabalham, sofrem, mas que dançam e dançando educam e vivem. Essas mulheres e homens esboçam nas suas falas, gestos, posturas, 0 prazer que as brincadeiras lhes proporcionam. Esse prazer imbrica-se com os seus corpos, falar nesses prazeres é, ao mesmo tempo, falar delas. O sentimento em poder dar continuidade a essas brincadeiras está relacionado à continuidade das suas vidas, é o que as move, é o que dá sentido ao viver.

\section{CONCLUSÃO}

Os brincantes pesquisados se encontram desmotivados, desvalorizados e preocupados com a fragilidade com que as brincadeiras se encontram na região, tais como: inexistência de grupos infantis, falta de apoio público (logístico e financeiro), desmotivação do próprio grupo, entre outros motivos. Favorecer o espaço da pesquisa para escutá-los, dialogar com eles sobre a importância da visibilidade dos seus conhecimentos adquiridos para a educação institucionalizada, propor momentos de socialização intergeracional foram algumas das propostas efetivadas durante a trajetória da pesquisa no último ano. Nas falas dos brincantes, geralmente dispostos a colaborar com o diálogo, percebemos o desabrochar de muita sensibilidade, esta expressa pelo corpo que recuava, que alterava o timbre de voz, que passava a mão no rosto, que desatava a rir, que chorava, enfim, percebemos existir uma memória que ali se expressava, que constituía os ossos, o ventre, a alma e a carne dessas pessoas.

Este trabalho reconhece uma Educação através das ações educativas dos velhos mestres brincantes do território do Mato Grande/RN. Essas ações educativas, denominadas pelos brincantes de brincadeiras, constituem-se nas narrativas dos Contos, nas cantorias, nas danças e no sentimento do viver que essas brincadeiras lhes proporcionam no envelhecimento. Uma Educação fundada pela tradição oral, nos seus desdobramentos da voz, gestos e performance.

A performance é percebida como uma comunicação que, ao comunicar, marca e transforma o conhecimento, modo imediato a um acontecimento oral e gestual, como assinala Zumthor (1993). Esse autor também aponta que a performance, além de se ligar ao corpo, liga-se ao espaço pelo corpo. É pela transmissão da voz, imbuída de gestos, que os personagens das brincadeiras pesquisadas no Mato Grande tornam-se presença. É pela percepção de quem escuta e vê e se envolve com a performance dos brincantes que os corpos se misturam, os sentimentos se entrelaçam. Essa reunião entre brincantes, organizadores, o público que assiste a eles, a sabedoria e astúcias que os mestres utilizam para comandar a brincadeira, a motivação dos brincantes em comunicar ritos e mitos, o espaço em que estão inseridos, o ambiente que se forma, a leitura que as pessoas fazem desses movimentos de corpos que, ao dançarem, provocam prazeres, remetem à denominação de "escola de vida" utilizada por Porpino (2006), a partir de Morin, sobre uma estética do dançar. E ela complementa: 
Entendemos também como verdadeiras escolas de vida as danças populares rurais e urbanas, que propiciam a integração de seus componentes na busca da vivência estética do dançar, mediada por todo um contexto também estético, de preparação de seus rituais, incluindo-se desde o planejamento dos ensaios, a confecção de vestimentas, a preparação do ambiente cênico, dentre outros. Tais experiências guardam em si possibilidades educativas que vão além do ensino formal, que são vividas informalmente, e até mesmo transmitidas e recriadas de geração em geração, como no caso das danças mais tradicionais (PORPINO, 2006, p. 114).

Danças que contam a história do lugar, que se misturam aos conhecimentos herdados da tradição e às inovações da contemporaneidade, perpassando o tempo e transmitindo signos, símbolos e ritos. Nesse desbravamento pelo Mato grande, conhecemos sábios e saberes singulares, múltiplos, originais, tradicionais, que precisávamos descrever, problematizar, discutir, religar e reorganizar a educação institucional.

Sentimos a necessidade de aproximar esses sábios dos jovens, de trocar idéias, conhecimentos, socializar uma visão de mundo que não seja impregnada apenas de velocidade, de progresso, de acúmulo de informações, de escrita, de manuseio de aparelhos eletrônicos, de apelo narcísico da beleza, de individualidade, de racionalidade, de formalidade, mas também de poder estabelecer espaços de convivência onde os velhos brincantes, através das suas brincadeiras, possam compartilhar criatividade, oralidade, união, conhecimento, coletividade, observação da natureza, enfim, provocar uma desordem de encadeamentos, reflexões e proposições para os jovens, que estão na escola, reconhecerem que podem ser estabelecidas relações de aprendizagem a partir da tradição oral. Com a tessitura deste trabalho, pretendemos acrescentar a voz viva dos velhos mestres brincantes, seja através das suas experiências com as danças, das suas nuances com os contos, das suas narrativas sobre as brincadeiras, seja com a melodia dos cantos.

Pensamos que este estudo possa ser ampliado, que possamos enveredar por outros lugares, identificar e dar voz a outros brincantes, conhecer outras brincadeiras pelo Rio Grande do Norte, registrando a pluralidade cultural que o estado possui, que atualmente se encontra em alguma voz silenciada, em algum corpo imobilizado, em alguma memória esquecida.

Por fim, este trabalho, apesar de arrematado, não se encerra aqui, ele indica alguns caminhos a percorrer, outros territórios a desbravar, outros brincantes a conhecer. Inúmeras brincadeiras a registrar, outros saberes ao narrar. Assim, iremos conhecendo a nossa história nestas terras de gente de guerra.

\section{REFERÊNCIAS BIBLIOGRÁFICAS}

1. ANDRADE, M. Danças dramáticas do Brasil. Belo Horizonte: Itatiaia, 2002.

2. AUGÉ, M. Por uma antropologia da mobilidade. Tradução de Bruno Cesar Cavalcanti e Rachel Rocha de A. Barros; revisão Maria Stela Torres B. Lameiras Maceió, EDUFAL, Unesp , 2010.

3. BENJAMIN, W.. Experiência e pobreza. In: obras escolhidas I: magia, técnica, arte e política. Tradução de Sergio Paulo Rouanet. São Paulo: Brasiliense, 1996.

4. CASCUDO, C. Dicionário do folclore brasileiro. Rio de Janeiro: Ediouro, 2012. 
5. DE CERTEAU, M. A invenção do cotidiano:1.Artes de fazer. Tradução de Ephrain Ferreira Alves. Petrópolis, RJ: Vozes, 2012..

6. GARAUDY, R. Dançar a vida. Tradução de Antonio Guimarães Filho e Gloria Mariani - Rio de Janeiro: Nova Fronteira, 1980.

7. INSTITUTO BRASILEIRO DE GEOGRAFIA E ESTATístICA. Censo demográfico de 2010. Rio de Janeiro.

8. MEDEIROS, R. M. Uma educação tecida no corpo.- São Paulo: Annablume, 2010.

9. PoRPINO, K. Dança é educação: interfaces entre corporeidade e estética. NATAL: EDUFRN 2006.

10. VAZ, A. Memória e Progresso. Corpo e História. Em Soares, C. L, 2001.

11. VIANA, R. N. O bumba-meu-boi como fenômeno estético. 177 f. tese (doutorado em educação) - Universidade Federal do Rio Grande do Norte, Natal, 2006.

12. VIEIRA, M. Pastoril: uma educação celebrada no corpo e no riso. Jundiaí: Paco Editorial, 2012.

13. ZUMTHOR, P. Introdução a Poesia Oral. Tradução de Jerusa Pires Ferreira, Maria Lucia Diniz Pochat, Maria Inês de Almeida. Belo Horizonte: Editora UFMG, 2010.

14. ___ Escritura e Nomadismo: entrevistas e ensaios. Tradução de Jerusa Pires Ferreira, Sonia Queiroz Cotia, SP: Ateliê Editorial, 2005.

15. __ Performance, Recepção, Leitura. Tradução de Jerusa Pires Ferreira, Suely Fenerich. Cosacnaify, 1993.

16. ___ A Letra e a Voz: a "literatura" medieval. São Paulo: Companhia das Letras,1993. 